\title{
Post-traumatic myositis ossificans
}

\author{
Author: \\ John M. Zietkiewicz ${ }^{1}$ \\ Affiliation: \\ ${ }^{1}$ Lake, Smit and Partners, \\ Durban, South Africa \\ Correspondence to: \\ John Zietkiewicz \\ Email: \\ ziets@lakesmit.co.za \\ Postal address: \\ Lake Smit and Partners, \\ Private Bag X08, Overport \\ 4067, South Africa \\ Dates: \\ Received: 24 July 2014 \\ Accepted: 17 Oct. 2014 \\ Published: 09. Dec 2014 \\ How to cite this article: \\ Zietkiewicz, JM. Post- \\ traumatic myositis ossificans. \\ S Afr J Rad. 2014;18(2); Art. \\ \#701, 3 pages. http://dx.doi/ \\ org/10.4102/sajr.v18i2.701

\section{Copyright:} \\ (C) 2014. The Authors. \\ Licensee: AOSIS \\ OpenJournals. This work \\ is licensed under the \\ Creative Commons \\ Attribution License.
}

Read online:
Post-traumatic myositis ossificans (PTMO) is characterised by abnormal heterotopic bone formation involving striated muscle. PTMO is usually associated with trauma and is most common in the second and third decades. An important teaching point is that in the early or subacute phase, clinical and imaging features can mimic a soft-tissue sarcoma. A combination of imaging modalities is required to evaluate the muscle lesion.

\section{Case report}

A 19-year-old man was referred for a magnetic resonance imaging (MRI) scan of his right elbow. He presented with a large, hard mass anteriorly situated in the right elbow with an associated flexion deformity. There was a history of trauma following a motor vehicle accident four months previously. Initial radiographs were normal. A second set of radiographs obtained four weeks later demonstrated a subtle soft-tissue mass with subtle mineralisation anterior to the right elbow (Figure 1). The MRI four months post injury demonstrated a large mass in the anterior cubital fossa that corresponded with the brachialis muscle. The mass had central signal intensity isointense to fat on the T1W (Figure 2) and T2W images. These features represent bone marrow surrounded by a low-signal-intensity rim of lamellar bone.

\section{Discussion}

Post-traumatic myositis ossificans (PTMO) is the most common form of myositis ossificans. ${ }^{1}$ PTMO frequently follows a history of trauma, with a predilection for anterior, proximal muscle groups in the thigh and arm. ${ }^{1,2}$ The histological evolution of PTMO parallels the radiographic or computed tomography $(\mathrm{CT})$ evolution and MRI appearances. ${ }^{3,4}$ Imaging choices are usually limited to conventional radiography, ultrasound and CT. ${ }^{1,2}$ MRI is not commonly performed.

\section{Conventional radiographs}

A localised periosteal reaction secondary to a subperiosteal haematoma may be seen within 7-10 days. Over the next few weeks, subtle soft-tissue mineralisation that becomes coarser, maturing from the periphery, is noted. Within two months, a well-defined cortex is seen peripherally. ${ }^{1,5,6}$ There is eventual mature heterotopic bone formation (Figure 3). Calcifications typically lie parallel to the shaft of long bones or the long axis of a muscle (as in this case). This is an important distinguishing feature from non-benign bone lesions. ${ }^{1}$

\section{Ultrasound}

In the first few weeks, PTMO has a non-specific appearance. A heterogeneous, hypoechoic area within the muscle is noted, often with associated fluid collections. Later, as the lesion matures, a hyperechoic peripheral rim reflecting calcification develops. ${ }^{7}$ An important imaging characteristic is the demonstration of normal muscle between bone and the mass, distinguishing it from a parosteal sarcoma. ${ }^{7}$

\section{Computed tomography}

$\mathrm{CT}$ is the imaging modality of choice because it optimally demonstrates the cross-sectional zonal pattern. In the first few weeks, CT shows soft-tissue swelling without calcification. After several weeks, a centrifugal zonal maturation pattern develops with the centre remaining isodense to muscle and a developing rim calcification which continues to mature. ${ }^{1,3,6,8} \mathrm{CT}$ is valuable in evaluating a periosteal reaction and lack of continuity with underlying cortex, helping to distinguish PTMO from parosteal sarcoma. ${ }^{1}$ 


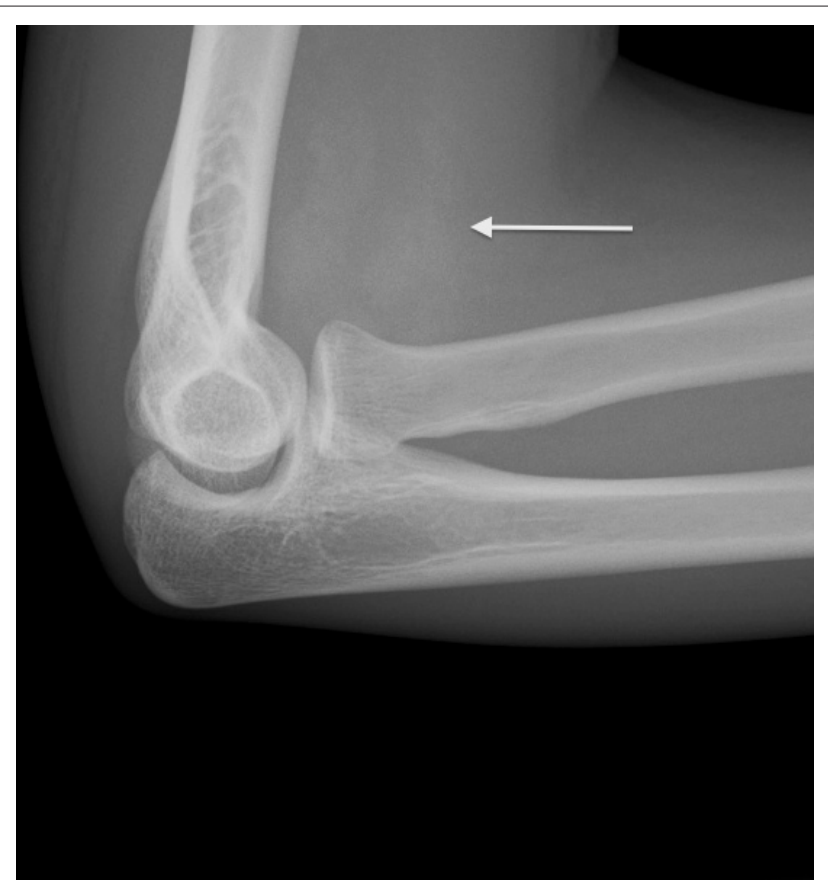

FIGURE 1: Lateral radiograph demonstrates subtle soft-tissue mineralisation (arrow) anterior to the elbow joint.

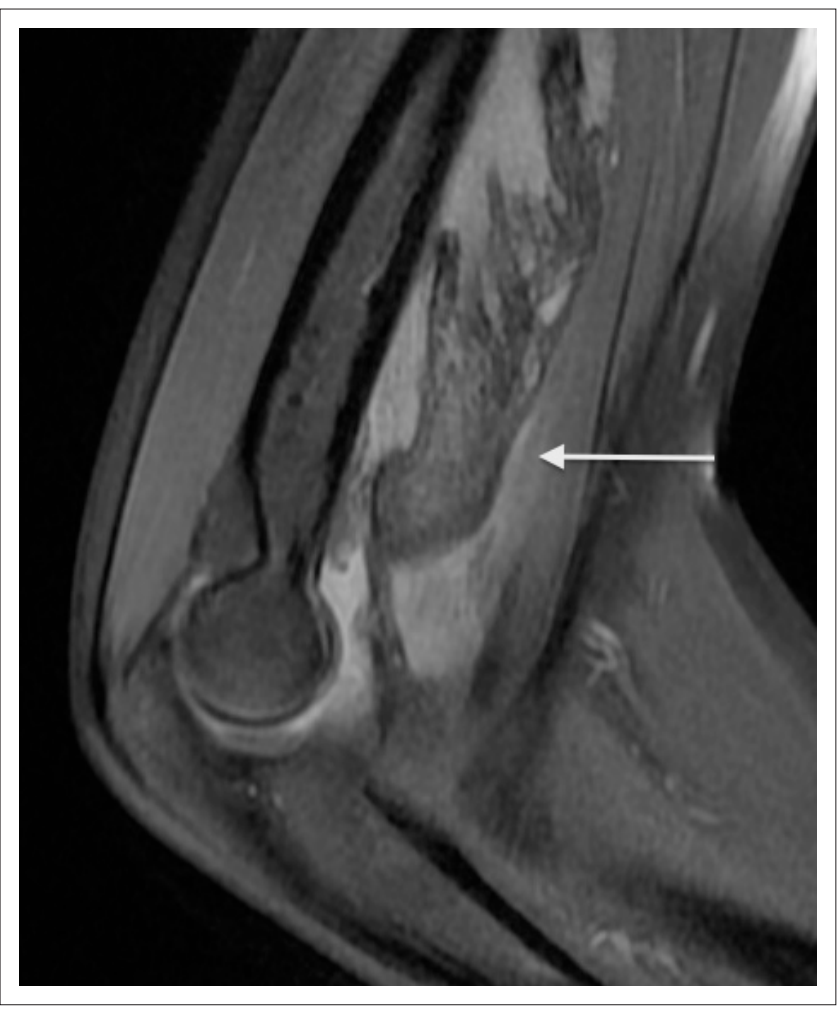

FIGURE 2: T1W sagittal image demonstrates a mass (arrow), within the right brachialis muscle, isointense to fat with a low-signal-intensity rim of lamellar bone.

\section{Isotope bone scans}

Radionuclide bone scanning (Technetium 99mdiphosphonate) is sensitive but largely non-specific. ${ }^{1}$ Early PTMO lesions show increased uptake in all phases. ${ }^{1}$ As the lesion matures, there is a progressive decrease in tracer uptake.

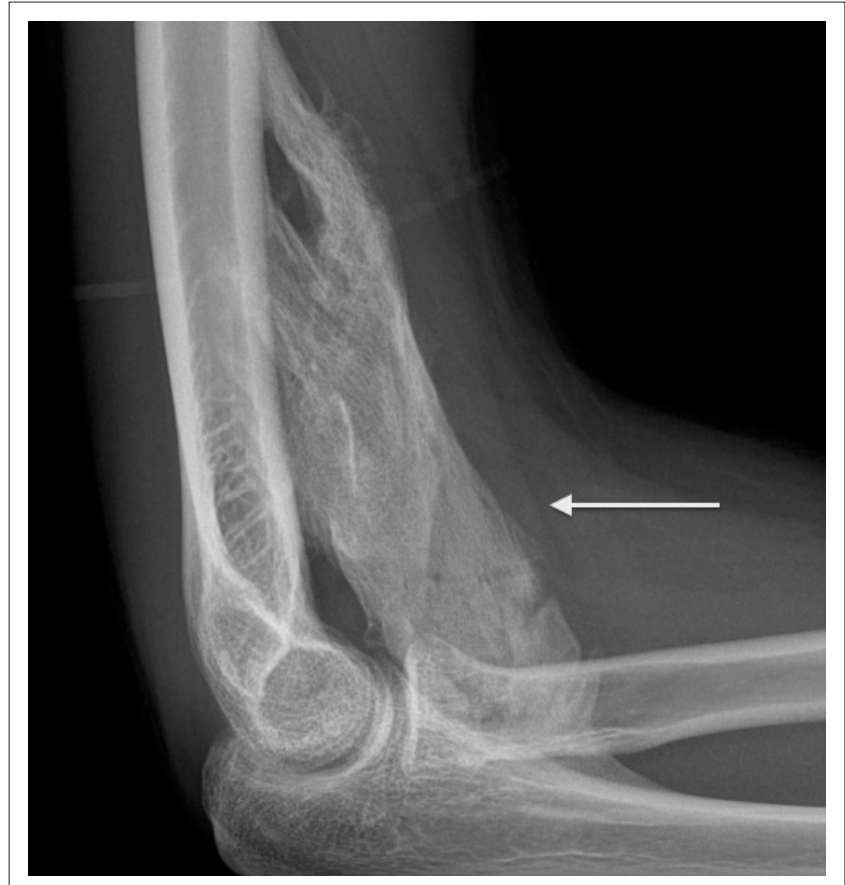

FIGURE 3: Lateral radiograph of the elbow demonstrates mature heterotopic soft-tissue bone formation (arrow).

\section{Magnetic resonance imaging}

An early PTMO lesion can mimic a soft-tissue tumour. Intense perilesional muscle oedema is a common feature not usually seen in sarcomas and is an important diagnostic finding. ${ }^{1}$ Acute/subacute lesions less than eight weeks old are isointense to muscle on T1W images and of mixed signal (mainly high) on $\mathrm{T} 2 \mathrm{~W}$ images with large areas of perilesional oedema and enhancement. ${ }^{1,2,3,4}$ These lesions can be inappropriately biopsied and excised.

Lesions greater than eight weeks old have two different patterns on MRI: (1) central signal intensity that is isointense with fat on both T1W and T2W images, representing bone marrow surrounded by a low-signal-intensity rim of lamellar bone; and (2) diffuse intermediate signal intensity on T1W images and slightly higher on T2W images, representing fibrosis. ${ }^{3}$

\section{Differential diagnosis}

In the acute/subacute setting, a muscle abscess, softtissue sarcoma and focal myositis are considerations. In more mature lesions with more bone formation, parosteal osteosarcoma, osteochondroma, chronic avulsion injuries and tumoral calcinosis are considerations. ${ }^{1,9}$

\section{Treatment}

PTMO is usually self-limiting and is treated conservatively. Further treatment options include active early mobilisation, physiotherapy and extracorporeal shockwave therapy. ${ }^{10}$ Surgery, as in this case, may be considered when lesions cause disfigurement, mechanical limitation and impingement on neurovascular structures. ${ }^{1}$ 


\section{Conclusion}

Myositis ossificans represents heterotopic formation of non-neoplastic bone and cartilage in soft tissue. It is usually post-traumatic, but the trauma can be minor. Pain is a common feature in an evolving lesion. PTMO evolves over time, with different imaging characteristics correlating with the age of the pathology. MRI scans should always be interpreted in conjunction with conventional radiographs and CT scans.

\section{Acknowledgements}

\section{Competing interests}

The author declare that he has no financial or personal relationship(s) that may have inappropriately influenced him in writing this article.

\section{References}

1. Tyler $P$, Saifuddin A. The imaging of myositis ossificans. Semin Musculoskelet Radiol. 2010;14(2):201-216. http://dx.doi.org/10.1055/s-0030-1253161

2. Stoller DW. Magnetic resonance imaging in orthopaedics and sports medicine. 3rd edn. Philadelphia: Lippincott Williams and Wilkins, 2007; p. 2154-2157.

3. Helms CA, Major NM, Anderson MW, Kaplan PA, Dussault R. Musculoskeletal MRI. 2nd edn. Philadelphia: Saunders Élsevier, 2009; p. 66-67.

4. Kansdorf MJ, Meis JM, Jelinek JS. Myositis ossificans: MR appearance with radiologic-pathologic correlation. Am J Roentgenol. 1991;157(6):1243-1248. http://dx.doi.org/10.2214/ajr.157.6.1950874

5. Helms CA. Fundamentals of skeletal radiology. 3rd edn. Philadelphia: Elsevier, 2005; p 55.

6. Anderson J, Read J. Atlas of imaging in sports medicine. 2nd edn. New York: McGraw Hill, 2008; p. 338-339.

7. Bianchi S, Martinoli C. Ultrasound of the musculoskeletal system. New York: Springer, 2007; p. 628-629.

8. Shirkhoda A, Armi AR, Bis KG, Makris J, Irwin RB, Shetty AN. MR imaging of myositis ossificans: Variable patterns at different stages. J Magn Reson Imaging. 1995;5(3):287-

9. Manaster BJ, May DA, Disler DG. Musculoskeletal imaging: The requisites. 3rd edn. Philadelphia: Elsevier, 2007; p. 523-525.

10. Buselli $P$, Coco V, Notarnicola A, et al. Shock waves in the treatment of posttraumatic myositis ossificans. Ultrasound Med Biol. 2010;36(3):397-409. http:// dx.doi.org/10.1016/j.ultrasmedbio.2009.11.007 